\title{
CHÁVENAS À BRASILEIRA: A GOVERNANTA INGLESA NO ROMANCE A MÃO E A LUVA,DE MACHADO DE ASSIS*
}

\author{
Rodrigo Silva Trindade \\ Universidade de São Paulo \\ São Paulo (SP), Brasil
}

\begin{abstract}
Resumo: O objetivo deste artigo é realizar um estudo sobre a personagem Mrs. Oswald, do romance A mão e a luva, de Machado de Assis, levando em conta a presença dessa personagem-tipo - a governanta - nos romances ingleses, em associação com a tradição do agregado presente na sociedade brasileira e, consequentemente, na literatura machadiana. Com isso, pretende-se observar quais são as implicações da presença dessa figura específica no romance em estudo.
\end{abstract}

Palavras-chave: A mão e a luva; romance; literatura brasileira; governanta; literatura inglesa.

\section{Brazilian teacups: the English governess in the novel A mão e a luva, by Machado de Assis}

\begin{abstract}
This article aims at studying Mrs. Oswald, a character of the novel A mão e a luva, written by Machado de Assis, considering the presence of this character - the governess - in the English novels, producing an association with the lodger's tradition in the Brazilian society, and, thereafter, in Machado de Assis' literature. Furthermore, this study intents to detect the implications of this specific figure in the novel under study.
\end{abstract}

Keywords: A mão e a luva; novel; Brazilian literature; governess; English literature.

Podemos verificar na obra de Machado de Assis, e este já é um ponto pacífico entre os críticos, o consistente diálogo que o escritor estabelece com a literatura universal. O próprio autor em vários momentos de suas narrativas dá indícios de seu repertório de

\footnotetext{
* Este artigo deriva do projeto de Iniciação Científica apresentado em 2008 na FFLCH-USP, sob orientação do Prof. Dr. Hélio de Seixas Guimarães, intitulado "A figura inglesa na ordem escravocrata brasileira: um estudo sobre a personagem Mrs. Oswald em A mão e a luva, de Machado de Assis".
}

http://machadodeassis.net/revista/numero11/rev_num11_artigo05.pdf 
leitura ao comparar sua obra com escritos sagrados como a Bíblia, dialogar com nomes canônicos como Shakespeare, Walter Scott, Stendhal, Victor Hugo, Sterne, Thackeray, entre outros.

Outro dado bastante presente na obra do escritor é a abordagem que este faz dos temas sociais. Machado de Assis é mestre em lidar com as incongruências da sociedade brasileira, em analisar as incoerências da burguesia nas relações de poder do universo patriarcal. Em suma, a obra machadiana ocupa-se em muitos momentos em revelar os bastidores da classe dominante no período do Segundo Reinado.

Ainda que tais abordagens sejam mais notáveis a partir de Memórias póstumas de Brás Cubas, já nos primeiros romances do escritor são observadas manifestações dessa temática. Em A mão e a luva, segundo romance do autor, publicado em 1874, verifica-se a presença de uma personagem estrangeira, o que constitui dado importante e pertinente ao estudo da obra machadiana. Pretendemos com este artigo deter-nos na análise de uma personagem que parece condensar na sua construção uma série de elementos relevantes para a interpretação de A mão e a luva: Mrs. Oswald.

Personagem marginal que vive sob a égide de uma matriarca e à mercê de um sistema contraditório em si mesmo, a governanta - típica representação de uma figura inglesa - se vale de vários artifícios para se fazer uma presença necessária no lar de sua protetora. Para analisarmos essa agregada, devemos considerar o fato de que ela se encontra em uma posição intermediária, sob diferentes perspectivas:

a) levando em conta o gênero literário no qual está inserida, a personagem marca o lugar do país que produziu uma das matrizes do gênero romance na composição do universo ficcional brasileiro. Constitui-se um dado relevante para a pesquisa a presença simbólica da Inglaterra, representando a Europa liberal, na produção literária de um país que tinha na escravidão um dos seus alicerces;

b) levando em conta o universo familiar da burguesia carioca, a personagem está em um lugar social entre a protegida Guiomar e a matriarca - a baronesa. Por fim, na galeria de personagens do romance machadiano, Mrs. Oswald também parece estabelecer 
uma espécie de ponte entre os agregados da primeira fase, que têm início com o parasita Viana, do romance Ressurreição, publicado em 1872, e seu mais célebre representante dos romances da fase madura, José Dias, de Dom Casmurro, publicado em 1899.

Adentraremos o estudo da personagem por duas vias. Trataremos primeiramente de dois romances que servirão como referência sobre a construção da governanta e dos demais tipos de agregados na ficção inglesa do século XIX: Mansfield Park, de Jane Austen, e Jane Eyre, de Charlotte Brontë. Em seguida, analisaremos a personagem Mrs. Oswald à luz de obras da crítica machadiana, especialmente Ao vencedor as batatas, de Roberto Schwarz.

Mansfield Park, de 1814, é um romance que tem como cenário a propriedade de Mansfield, para onde é levada a jovem Fanny Price, sobrinha de Mrs. e Mr. Bertram, aos dez anos de idade. Como uma espécie de caridade, o casal burguês de favorável condição social acolhe a jovem. Também em Mansfield vive outra agregada: Mrs. Norris. Viúva e sem filhos, a irmã de Mrs. Bertram assume a função de algoz da recém-chegada desde os primeiros momentos da trama.

Inserida em um contexto estranho aos seus costumes, a jovem tem ao seu redor personagens que de certa forma ocupam um espaço similar ao seu, levando em conta o fato de que ela não faz parte da família, no seu sentido estrito. Boa parte de seus percalços é decorrente da ação de Mrs. Norris na trama, seja esta exercendo influência prejudicial à jovem junto àqueles que a mantêm, seja impondo-lhe tarefas incompatíveis com a sua frágil estrutura física. O temperamento manso de Fanny não permite que ela seja autônoma no tocante a Mrs. Norris: sempre está à mercê de suas ordens, que são acatadas ainda que afrontem as suas necessidades.

Temos então Fanny como a agregada "adotada" pela família de Mansfield que modifica a ordem familiar a partir de sua chegada, o que contraria sua tia e outra agregada, "não oficial": Mrs. Norris. Todo o esforço da viúva do clérigo Norris está em diminuir ao máximo o grau de importância de Fanny dentro da família e, na mesma medida, aumentar o seu. 
Ainda em uma condição parecida temos, no mesmo romance, a personagem Miss Lee, responsável pela educação das filhas dos Bertram e também de Fanny Price, nos momentos iniciais do romance.

Jane Eyre, de 1847,nos traz, narrada em primeira pessoa, a história da personagem homônima, desde sua primeira infância, os anos de orfanato, até o seu trabalho na mansão do milionário Rochester. Pelo seu olhar enxergamos o universo da preceptora dentro da família na narrativa inglesa.

Jane é uma moça órfã enviada pela tia a um orfanato, onde vive toda a sua infância e adolescência. Garota sensível e inteligente, aprende rapidamente o francês e as atribuições cabíveis a uma mulher no século XIX, como costurar, bordar, pintar e os demais cuidados do lar. Já na juventude, após passar um período como funcionária de Lowood, decide abandonar o lugar de tantas lembranças tristes e felizes proporcionadas respectivamente por Mr. Brocklehurst, cruel e insensível mantenedor do orfanato, e Miss Temple, doce e amorosa educadora-chefe da instituição, para tentar se estabelecer como governanta na casa do milionário Rochester.

Além de Jane Eyre, nos interessa verificar a presença da personagem Mrs. Fairfax, responsável pela administração da mansão. A governanta foi a encarregada da contratação de Jane Eyre e de orientá-la em suas atribuições de preceptora da francesinha Adèle, filha de um relacionamento extraconjugal de Rochester. Mrs. Fairfax está numa zona intermédia entre o proprietário da mansão e os seus demais criados. Todas as tarefas burocráticas são a ela delegadas. Salvo um parentesco distante, as relações entre "patrão" e "empregada" são estritamente profissionais. A governanta se autodefine como uma "gerente do lar".

Coincidentemente ou não, Mrs. Fairfax é viúva de um clérigo e, a exemplo de Mrs. Norris, também possui um grau de parentesco com o dono da propriedade. $\mathrm{O}$ que as diferencia é que a primeira abre mão das vantagens que uma relação de parentesco pode 
trazer enquanto a outra opta por chegar ao limiar entre o "favor" e as relações efetivamente profissionais, não abdicando da esperança de ser vista como uma lady. ${ }^{1}$

Faz-se necessário aqui diferenciar os termos "preceptora" e "governanta", que são por vezes utilizados de modo indiscriminado tanto nas traduções como pela crítica, para designar personagens com funções sociais idênticas ou que possuem atribuições que as diferenciam. Isso se deve ao fato de que na Inglaterra e, por consequência, nos romances ingleses, governess é a palavra que define tanto uma como a outra.

Nas traduções para o português, Jane Eyre é nomeada governanta, no entanto observamos que suas atribuições se restringem aos cuidados da pequena Adèle. Assim sendo, desenvolve também as tarefas de preceptora. Esse tipo de mão-de-obra é voltado para assuntos pedagógicos, já que aos mais abastados representava certo status ter seus filhos educados por uma profissional em período integral.

A preceptora é a responsável por ensinar às crianças da família uma língua estrangeira (o francês, requisito mínimo da boa educação no século XIX), pintura, bordado, noções de aritmética, boas maneiras e demais conteúdos necessários a uma moça cujos pais desejam que cresça bem educada, segundo os moldes da sociedade vitoriana. As personagens que têm essa incumbência nos romances apresentados são Jane Eyre, no romance homônimo de Charlotte Brontë, e Miss Lee, personagem secundária de Mansfield Park, de Jane Austen.

Dessa forma, verificamos que preceptora e governanta efetivamente não desenvolvem as mesmas funções. É possível observar nesse nosso pequeno recorte que a governanta é uma mulher com mais experiência - geralmente uma senhora com mais de quarenta anos -,enquanto a preceptora normalmente é uma senhorita recém-saída dos estudos,que não estabeleceu matrimônio e não detém recursos para obter independência

\footnotetext{
${ }^{1}$ Os termos "lady" e "gentleman" originalmente eram atribuídos por hereditariedade à aristocracia. Com o desejo de apropriar-se da terminologia, a burguesia emergente designava os homens que ascendiam através do trabalho porgentlemen. Ao contrário, uma mulher que oferecesse sua mão-de-obra a qualquer que fosse a atividade não poderia ser denominada lady, conforme observado por: MONTEIRO, Maria Conceição. Sombra errante: a preceptora na narrativa inglesa do século XIX. Niterói: Eduff, 2000. p.19. Em Mansfield Park, Maria Bertram é sempre tratada por lady, enquanto que sua irmã Mrs. Norris em nenhum momento é assim chamada.
} 
financeira. Levando em conta que preceptora é aquela responsável por cuidar e educar as crianças da casa, no nosso rol de personagens ela é representada por Miss Lee e Jane Eyre. Governanta é como se define Mrs. Fairfax. A ela cabe delegar responsabilidades aos demais criados, administrar questões relativas à comodidade do patrão e, de certa maneira, ser o elemento que representa a propriedade na ausência do proprietário.

Há também aquelas personagens que não possuem função específica, ou seja, não possuem obrigações profissionais diárias, simplesmente se mantêm na esfera familiar que originalmente não é a sua, por não terem recursos próprios ou não possuírem pai ou marido que lhes garanta o sustento. Por não terem um vínculo profissional, a estas chamaremos simplesmente de agregadas. Em nosso estudo, Fanny Price e Mrs. Norris.

Definido o campo de ação das governantas e preceptoras inglesas, podemos situar melhor a agregada machadiana. Mrs. Oswald entra em cena no quarto capítulo do romance, sob o rótulo de Latet anguis, "serpente escondida" em latim, o que anuncia seu modo de ação no espaço do romance. Cerca de dez anos mais jovem que a baronesa, sua protetora, a inglesa é apresentada como uma "dama de companhia"; a rigor, uma governanta.

Após a perda da filha Henriqueta, a baronesa teve na inglesa uma companheira quase única, o que rendeu a Mrs. Oswald a posição de "alma da casa". Mulher sagaz, inteligente e um tanto quanto rasteira, ainda que de boa índole, esta se dedica ao propósito de ter restabelecida a sua zona de influência na casa, perdida após a chegada de Guiomar, afilhada da baronesa que passaria a ser criada como filha desta. Marcelo Pen Parreira aponta para o dado da origem como relevante para a compreensão do perfil construído no romance:

Interessante notar que é uma inglesa a primeira personagem ostensivamente manipuladora e ardilosa dos romances machadianos. Teria 
Machado imaginado que na terra de Walter Scott, ${ }^{2}$ autor que a dama de companhia lia em volume grosso da edição Constable, abundavam os tipos manhosos? $?^{3}$

Mrs. Oswald é vista como a primeira personagem secundária de relevância no romance de Machado de Assis. Efetivamente apresentada como agregada, a dama de companhia é o primeiro "satélite" a influenciar com relevância a trama central, que diz respeito à família proprietária. Aliás, parece haver na crítica machadiana uma subvalorização das personagens da chamada primeira fase que exercem funções sociais similares às das da segunda. Anterior a $A$ mão e a luva, que traz Mrs. Oswald como a "serviçal influente", Ressurreição traz o embrião do agregado nos romances do escritor.

Embora no romance de estreia não conste explicitamente a temática das relações de poder entre as personagens, existe de maneira discreta uma prefiguração das personagens tidas como marginais, e essa é personificada na personagem Viana. Irmão de Lívia - par amoroso de Félix -, Viana entra em cena no primeiro capítulo e é descrito pelo narrador como um homem de interesses, tipificado de modo a cumprir a função de parasita até o final da obra. Viana demonstra interesse no processo que visa unir sua irmã a Félix e o faz a princípio de maneira muito dedicada, porém com alguma oscilação, de acordo com a sua conveniência.

Incompleta ou não, a caracterização da personagem Mrs. Oswald se dá de modo curioso. Diferentemente de Viana em Ressurreição, a inglesa apresenta uma relação de dependência. Seu campo de ação é maior, já que se encontra na casa onde se passam os conflitos principais e sua zona de influência é proporcional à quase onipresença na "tela", tal como Machado de Assis nomeou o espaço do romance.

A inglesa tem uma faceta bajuladora que é conveniente à sua manutenção no universo da matriarca: "Pela minha parte, oxalá pudesse contribuir para a completa

\footnotetext{
${ }^{2}$ Walter Scott é, na verdade, um escritor escocês.

${ }^{3}$ PARREIRA, Marcelo Pen. Estratégias do falso: realidade possível em Henry James e Machado de Assis. Tese de Doutorado, FFLCH / USP. São Paulo, 2007.p. 124.
} 
felicidade desta família, a quem devo tantos e tamanhos benefícios." ${ }^{4}$ Para sua infelicidade, Guiomar não a vê com simpatia. Consciente das aspirações de Mrs. Oswald, a jovem a trata de maneira rude. Dessa relação áspera, Roberto Schwarz infere uma resistência ao elemento estrangeiro: "Aliás, diga-se que de modo geral Mrs. Oswald é tratada com bastante xenofobia."

Estabelece-se entre Guiomar e Mrs. Oswald uma espécie de concorrência velada. Concorrência porque de um lado Guiomar aspira a saciar o seu desejo de grandeza através de um casamento bem-sucedido. A governanta, por sua vez, preocupa-se em recuperar o estatuto que outrora gozara junto à baronesa. Velada porque as duas não se agridem diretamente, e se o fazem é lançando mão da ironia, como nestas passagens: "Viva a minha rainha de Inglaterra!" 6 e "Dormiu bem a minha rainha de Inglaterra?"”Desta forma, "Mrs. Oswald lembra-lhe [a Guiomar], por inversão irônica, de sua natureza dependente, não mais do que a inglesa nesse sentido e que deveria, por isso, obedecer aos desejos da baronesa, nem que seja o de submeter-se a um casamento de conveniência..." ${ }^{8}$ Guiomar, por sua vez, não tem a necessidade de ser tão sutil. Recebendo os pedidos de desculpas de Mrs. Oswald por uma indiscrição cometida, profere a seguinte frase:"- Muito mal, interrompeu Guiomar; são cousas de família em que a senhora nada tem que ver." ${ }^{9}$

Para Mrs. Oswald, influenciar Guiomar é necessário. Seu sucesso na empreitada que assume - o matrimônio entre Jorge e a jovem - depende necessariamente de convencer a moça, persuadi-la, fazendo uso inclusive de mentiras, como na seguinte argumentação da governanta:

\footnotetext{
${ }^{4}$ Idem, p. 29.

${ }^{5}$ SCHWARZ, Roberto. Ao vencedor as batatas. São Paulo: Duas cidades; Editora 34, 2007. p. 114.

${ }^{6}$ ASSIS, Machado de. A mão e a luva. São Paulo: Ática, 1981.p. 30.

${ }^{7}$ Idem, p. 87.

${ }^{8}$ PARREIRA, Marcelo Pen. Estratégias do falso, cit., p. 124.

${ }^{9}$ ASSIS, Machado de. A mão e a luva, cit., p. 55.
}

http://machadodeassis.net/revista/numero11/rev_num11_artigo05.pdf 
- Pois bem, - continuou Mrs. Oswald abaixando a voz, como se alguém pudesse ouvi-la na solidão daquela alcova, e no silêncio profundo daquela casa, que toda dormia, - pois bem, eu lhe direi que por ela mesma tive notícia deste seu desejo. Quando eu percebi a paixão do Sr. Jorge, falei nisso a sua madrinha, gracejando na intimidade que ela me permite, e a senhora baronesa em vez de sorrir, como eu esperava que fizesse, ficou algum tempo pensativa e séria, até que rompeu nestas palavras: "Oh! Se Guiomar gostasse dele e viessem a casar-se, eu seria completamente feliz. Não tenho hoje outra ambição na terra. Há de ser a minha campanha". ${ }^{10}$

O leitor atento observará que a última afirmação atribuída à baronesa não era verdadeira. Ela faria bom gosto de uma possível união do casal, mas não que fosse esta sua "campanha". Ao leitor que não havia atentado para esta, digamos, sutil alteração no discurso da baronesa, o narrador se encarrega de informá-lo:"[...] porque nunca a baronesa dissera que tal casamento era a sua campanha, e Mrs. Oswald atribuiu-lhe esta frase mortal para todas as esperanças e sonhos da moça." ${ }^{11}$

Seguramente nada havia no casamento entre Guiomar e Jorge que beneficiaria Mrs. Oswald, além do desafio que tal empreitada representava; o desejo de fazer parte do processo que uniria o sobrinho à afilhada da baronesa devolveria a ela o prestígio perdido com a chegada de Guiomar.

Guiomar leva certa vantagem na guerra contra Mrs. Oswald. Se esta necessita "atacar" em duas frentes - a baronesa e a afilhada -, aquela goza de muito prestígio junto à madrinha e a mais ninguém paga tributo. Não depende em nada da governanta; pelo contrário, deseja apenas ver-se livre de suas "maquinações matrimoniais"; portanto, o sucesso de Guiomar não implica nenhuma obrigação junto a sua concorrente. Tendo sua posição enfraquecida no seio familiar, a governanta passa a apoiar os interesses de Jorge, sobrinho da baronesa, que visa casar-se com Guiomar. Consciente de que tal união seria do agrado de sua protetora, Mrs. Oswald age como uma típica alcoviteira.

As obrigações profissionais de Mrs. Oswald na residência são pouco comentadas. Em parte isso talvez se deva ao caráter breve da narrativa, que muitas vezes é classificada

\footnotetext{
${ }^{10}$ Idem, p.57.

${ }^{11}$ Idem, p. 69.
} 
como novela. Não é dispensada atenção à criadagem da casa, embora saibamos que ela exista por algumas breves alusões. O que mais se aproxima do que viriam a ser as atribuições da governanta está em uma passagem chave do romance:

- Mrs. Oswald -disse a baronesa -, vá ver se já deram de comer aos passarinhos.

A inglesa percebeu que estes passarinhos, naquele caso, eram uma pura metáfora, e que a baronesa nada mais fazia do que pedir-lhe delicadamente que se fosse embora. Todavia, não se deu por achada.

- Parece-me que não - disse ela -; vou já saber disso.

- Olhe -disse a baronesa quando ela já ia a meio caminho -; encosteme essas portas, e dê ordem para que ninguém nos interrompa. ${ }^{12}$

Desse emblemático trecho podemos inferir uma série de informações relativas ao sistema hierárquico dentro da casa. A primeira delas é que Mrs. Oswald não era efetivamente parte do círculo familiar: a exemplo de Mrs. Fairfax, em Jane Eyre, tratava-se de uma supervisora, uma gerente. Suas atribuições incluíam verificar se os demais criados, seguramente os escravos, haviam dado de comer aos pássaros. Como "encarregada-geral", cabia a ela também ordenar à criadagem ou a qualquer outra pessoa que a baronesa não fosse interrompida durante sua conversa com a afilhada.

Fanny Price provém de um berço que não lhe engrandece e é levada para viver junto dos tios em um lugar muito maior do que a sua imaginação poderia alcançar. Jovem e inexperiente, com medo de tudo e de todos, não consegue se libertar da opressão de sua tia, Mrs. Norris, responsável por seus padecimentos. Já Guiomar, personagem sem sobrenome e humilde de nascimento, é sagaz o suficiente para se estabelecer como uma figura importante dentro de uma casa onde reinaria absoluta sob as asas da bondosa madrinha, não fossem as intervenções despropositadas da governanta, que deseja reaver sua importância no seio da família.

\footnotetext{
${ }^{12}$ Idem, p. 89.
} 
As senhoras agregadas agem de modo bastante semelhante. Mrs. Norris é uma agregada de caráter duvidoso, uma presença muito mais imposta à família de Mansfield Park do que propriamente alguém que tenha sido incorporada a ela. A princípio vivia no presbitério, quando ainda estava em vida o marido. Quando ficou viúva, se mudou para uma das propriedades de seu cunhado.

[Mrs. Norris...] consolou-se da perda do marido com a convicção de que poderia muito bem viver sem ele; e para contrabalançar a redução de sua renda, empenhou-se cada vez mais em diminuir as despesas e viver na mais estrita economia. ${ }^{13}$

Mrs. Norris tinha muito evidente, além da necessidade de reconhecimento, um apego material, emblema do capitalismo não só no centro como na sua periferia . Guardava dinheiro sem que ninguém soubesse, funcionava como uma "ave de rapina", vivendo dos restos de Mansfield:

Desde que se tratasse de movimentar, falar e combinar planos ela estava sempre pronta e ninguém, melhor do que ela, sabia recomendar liberalidade aos outros; seu amor ao dinheiro era tão forte quanto a vontade de mandar e quando se tratava de despesas sabia muito bem guardar o seu para gastar o dos outros. ${ }^{14}$

Além de ser rasteira, a agregada tinha a característica de se fazer notada por suas opiniões e atitudes. A Mrs. Norris lhe aprazia unir casais segundo a sua conveniência, como no caso da sobrinha Maria, de quem gostava muito e queria que se casasse com $\mathrm{Mr}$. Rushworth. Decerto a união ocorreria sem que Mrs. Norris fizesse algo, no entanto ela se iludia ao pensar que havia sido responsável pelo matrimônio, inclusive no que tange aos preparativos. O casamento foi um fracasso, por conta do adultério de Maria com Mr.

\footnotetext{
${ }^{13}$ AUSTEN, Jane. Mansfield Park. Rio de Janeiro: José Olympio, 1958. p. 22.

${ }^{14}$ Idem, p. 9.
} 
Crawford, para desespero de Mrs. Norris. Não só a esposa infiel, mas também Julia causou um desgosto à família, unindo-se a um homem sem a aprovação do pai.

Conservador e beirando o tom pedagógico, o narrador de Mansfield Park julga e atribui a responsabilidade pelos passos mal dados pelas moças da família à intervenção maléfica de Mrs. Norris:

[Thomas Bertram] Depressa começou a compreender como pode ser desfavorável ao caráter dos jovens o contraste entre os dois diversos tratamentos que Maria e Julia haviam recebido em casa: a excessiva indulgência e lisonja da tia em oposição constante à severidade paterna. Viu quão mal ele raciocinara, supondo vencer o que havia de errado no sistema de Mrs. Norris pelo seu sistema oposto; viu claramente que não fizera senão aumentar o mal, ensinando-as a se reprimirem em sua presença, mantendo-lhes desconhecidas as suas tendências reais, e entregando-as à indulgência de uma criatura que só seria capaz de prendêlas graças à cegueira de sua afeição e aos excessos de adulação. ${ }^{15}$

O final de Mrs. Norris é melancólico. Parte para morar com Maria, a esposa infiel rejeitada pelo marido e pela família, sem deixar saudades a ninguém. Nisso a obra se mostra extremamente romântica, conservadoramente vitoriana. Estabelece uma punição àquela que tratou de fazer triste a vida da heroína da história (Fanny), que, por sua vez, tem um final feliz ao lado do homem que ama.

O arremate de $A$ mão e a luva se dá por outra via. Não há sanções às personagens e tudo termina na mesma lógica que parece ter conduzido todo o romance: a do arranjo. Ninguém sai efetivamente derrotado na história, tudo se arruma, se organiza. Vejamos como isso se dá.

Guiomar e Luís Alves efetivamente se casam e se dão por satisfeitos com o feliz matrimônio. A baronesa, embora quisesse que a afilhada se unisse ao sobrinho, bondosamente abandona à inclinação de seu coração e se satisfaz com a realização do desejo da moça. A Jorge e a Estevão, justifica o narrador, não faria maior diferença

\footnotetext{
${ }^{15}$ Idem, p. 391. Grifo nosso.
} 
casarem-se ou não com a mulher "amada", porque até mesmo esse amor era questionável, visto os dois se tratarem de espíritos volúveis e pouco obstinados. Desse modo, tudo se arranjou no estrato superior da sociedade. E Mrs. Oswald?

Aos mais deslocados na pirâmide social cabe maior esforço para manterem-se vivos sob a custódia dos seus protetores. Dessa forma, a governanta viu o resultado de seus trabalhos cair por terra, restando a ela se unir ao grupo dos vencedores. Faz uso mais uma vez da hipocrisia e da bajulação para continuar viva no universo doméstico: "Que quer? disse Mrs. Oswald. O coração não se pode dominar, nem há meio de impor-lhe um sentimento. D. Guiomar é uma santa criatura, ama deveras ao seu rival; há nada mais justo do que casá-los?"16

Com esta frase proferida a Jorge, Mrs. Oswald encerra de vez a sua participação no plano matrimonial do sobrinho da baronesa. Dessa maneira se obriga a aderir ao lado vencedor e não mede esforços para que isso seja percebido:

Mrs. Oswald igualmente se mostrava feliz - talvez ainda mais, porque era-o aparatosamente, como se quisesse resgatar as passadas culpas. Guiomar entendia a intenção latente das manifestações ruidosas com que ela andava a felicitá-la e bajulá-la; mas o dia não era de rancores nem de ressentimentos, e ela recebia sorrindo as cortesanices da inglesa. ${ }^{17}$

Guiomar, soberana da situação, grande vencedora da disputa retórico-psicológica estabelecida no ambiente doméstico desde a descoberta por parte da inglesa de sua conversa ao pé da cerca com Estevão, mantinha a sua política de não se indispor com a inglesa.

Após a aceitação de Luís Alves, elemento estranho à esfera familiar, como noivo de Guiomar, Mrs. Oswald adere ao "lado vencedor". Chega à conclusão de que o casamento entre Guiomar e o oponente de Jorge seria a coisa mais justa a ser feita.

\footnotetext{
${ }^{16}$ ASSIS, Machado de. A mão e a luva, cit., p. 93.

${ }^{17}$ Idem, p. 96.
} 
Verifica-se que a personagem oscila de um lado para o outro de acordo com a conveniência e demonstra ser sempre favorável à palavra final de sua protetora. Com a "serpente escondida", Machado de Assis projeta em Mrs. Oswald o artifício sutil, evidente e necessário a uma subalterna que precisa ser leve, por vezes imperceptível, para conquistar o mínimo que seja em um ambiente que não lhe é de todo favorável.

Podemos localizar Mrs. Oswald, no que tange às relações sociais que estabelece, entre Mrs. Fairfax - a governanta de Jane Eyre - e Mrs. Norris - a agregada de Mansfield Park. Se esta pretende gozar de certo prestígio fazendo parte do universo familiar do qual é uma espécie de parasita, aquela possui um laço de sangue que procura diminuir, rebaixando-se a simples figura de governanta, com um campo de ação bem delimitado.

Roberto Schwarz nomeou de "mecanismo do favor" as relações estabelecidas entre os homens livres e os proprietários, que nada mais são do que um modo de relação social que deriva da lógica escravocrata e que implica a assimilação imprópria de princípios do liberalismo europeu; ou seja, no Brasil - periferia do capitalismo - os proprietários adaptavam princípios europeus segundo suas conveniências. Os agregados, portanto, ocupam lugar relativamente parecido com o dos escravos, sem ferir o ideário liberal.

Em A mão e a luva, Mrs. Oswald representa de modo muito peculiar a construção do agregado na obra do escritor brasileiro. Sua presença na ficção implica uma série de consequências importantes para o entendimento e a análise do romance e, simbolicamente, da sociedade. A governanta machadiana é o elemento estranho dentro do espaço doméstico, que traz para a esfera da família a lógica mercantil proveniente do velho continente, adaptada à sua realidade assim como à de vários outros agregados no Brasil.

Machado de Assis parece trazer para o universo do romance, condensada numa só personagem, toda a incongruência e todo o conflito entre o ideário europeu e o espaço do Brasil escravocrata. Da fusão desses dois universos distintos surge uma governanta deslocada do seu espaço tradicional. Ela agora toma o chá das cinco pensando no modo de obter o pão no dia seguinte. Guiomar, também uma espécie de agregada, despreza os movimentos da inglesa, ao mesmo tempo em que não concorda com o matrimônio desejado por sua madrinha, manipulando-a e obtendo êxito em seu intento. 
$\mathrm{O}$ atento escritor percebe, problematiza e transpõe para a literatura, em forma de personagem, uma questão que passa inclusive pelo acidentado terreno da produção romanesca no Brasil - gênero que tem na Inglaterra uma de suas principais matrizes. Considerando esse dado, não é de se surpreender que seja inglês o elemento escolhido para representar literariamente parte da problemática.

Observando além da produção romanesca em terreno "impróprio", podemos pensar na galeria de agregados machadianos tomando por base o já citado Viana e o mais célebre representante: José Dias. Como sugere Silviano Santiago acerca de uma evolução das formas e dos temas desde Ressurreição até Dom Casmurro, podemos estabelecer uma espécie de genealogia das personagens.

O agregado de Dom Casmurro é também um elemento ardiloso no seio da família que o acolhe. Sua participação na trama principia com base em uma mentira. Apresentando-se como suposto médico, foi objeto da piedade da família Santiago e, após a morte do patriarca, a viúva D. Glória passa a ser fortemente influenciada pelas suas opiniões. Valendo-se de sua capacidade oratória, o agregado oscila entre o rechaço e o apoio ao relacionamento de Bentinho e Capitu. No primeiro momento, acredita que a promessa realizada por Dona Glória, que obrigava Bentinho a ser padre, deveria ser cumprida. Em seguida, passa a apoiar o jovem, com a esperança de obter uma viagem a Europa como uma espécie de tutor. $\mathrm{O}$ sonho não se realiza.

Na posição de José Dias, toda manobra era pensada com o objetivo de obter algum prestígio ou vantagem. Quando percebe que seria vencido no propósito de separar Bentinho e Capitu, dá um passo atrás e apoia a relação. Após o casamento de Bento, o agregado passa a tecer elogios a respeito da nova senhora Santiago. O conselheiro de D. Glória demonstra uma maior sagacidade do que Mrs. Oswald, pois enquanto esta se manteve firme no propósito que julgava ter maior possibilidade de sucesso, José Dias tinha a percepção de sua situação e maior capacidade de adaptação às alterações que lhe sobrevinham, o que o possibilitava lograr êxito ao lado dos vencedores, fossem eles qualquer uma das partes.

Mrs. Oswald seria, portanto, o primeiro grande ensaio de uma figura que teria posteriormente uma representação mais densa em José Dias. Em um misto de erudição, 
sagacidade, inteligência, flexibilidade, versatilidade e muito de servidão "herdados" em grande parte dessa personagem, o agregado de Dom Casmurro viria a ser composto posteriormente, dotado de maior complexidade, na mesma medida em que Machado de Assis aprimorava a problemática social em parte esboçada nos romances de primeira fase.

Referências:

ASSIS, Machado de. A mão e a luva. São Paulo: Ática, 1981. . Dom Casmurro. São Paulo: Círculo do livro, 1969. . Ressurreição. São Paulo: Ática, 1998.

AUSTEN, Jane. Mansfield Park. Rio de Janeiro: José Olympio, 1958.

BRONTË, Charlotte. Jane Eyre. Rio de Janeiro: Paz e Terra, 1996.

MONTEIRO, Maria Conceição. Sombra errante: a preceptora na narrativa inglesa do século XIX. Niterói: Eduff, 2000.

PARREIRA, Marcelo Pen. Estratégias do falso: realidade possível em Henry James e Machado de Assis. Tese de Doutorado, FFLCH / USP. São Paulo, 2007.

PEREIRA, Lúcia Miguel. Machado de Assis: estudo crítico e biográfico. São Paulo: Companhia Editora Nacional,1939.

SANTIAGO, Silviano. Retórica da verossimilhança. In: .Uma literatura nos trópicos: ensaios sobre dependência cultural. Rio de Janeiro: Rocco, 2000.

SCHWARZ, Roberto. Ao vencedor as batatas. São Paulo: Duas cidades; Editora 34, 2007.

WANDERLEY, Márcia Cavendish. A voz embargada: imagens da mulher em romances ingleses do século XIX. São Paulo: Edusp, 1996. 
Rodrigo Silva Trindade é bacharel e licenciado em Letras pela Universidade de São Paulo, mestrando em Literatura Brasileira também na FFLCH-USP com o projeto "Bemaventurados os que leem: formas simples em Esaú e Jacó, de Machado de Assis". Faz parte do grupo de pesquisa "A recepção crítica da obra de Machado de Assis". E-mail: r.trindade@outlook.com

Recebido: 11.03.2013

Aprovado: 17.06.2013 